\title{
Kajian Penentuan Arah Kiblat Secara Geodetis
}

\author{
Moehammad Awaluddin*, Bambang Darmo Yuwono, H. Hani’ah, Satrio Wicaksono \\ Program Studi Teknik Geodesi, Fakultas Teknik, Universitas Diponegoro, Universitas Diponegoro, \\ Jl. Prof. Soedharto, SH, Tembalang, Semarang, Indonesia 50275
}

\begin{abstract}
Abstrak
Kiblat merupakan arah penting Umat Muslim menghadapkan dirinya saat melakukan ibadah shalat. Pengukuran arah kiblat kemudian menjadi permasalahan ketika lokasi suatu tempat jauh dari Ka'bah karena tidak dapat dilakukan pengamatan penglihatan secara langsung. Oleh karena itu diperlukan metode yang tepat untuk menentukan arah kiblat di daerah yang jauh dari Ka'bah, dalam penelitian ini Kota Semarang. Makalah ini mengkaji besarnya perbedaan arah kiblat pada tiga bidang hitungan ellipsoid, bola dan Peta Mercator. Arah Kiblat pada ketiga bidang hitungan tersebut dibandingkan dengan arah kiblat hasil pengukuran rashdul qiblat. Arah kiblat hasil hitungan di atas ellipsoid yang sudah dikoreksi dengan di atas bola mempunyai perbedaan yang jauh lebih kecil yaitu sebesar 45, 7", jika dibandingkan dengan arah kiblat pada Peta Mercator. Perbedaan arah kiblat di atas ellipsoid yang sudah dikoreksi dengan arah kiblat hasil rashdul kiblat di lapangan sebesar 0" 7' 58,24". Sedangkan untuk selisih arah kiblat di atas bidang bola dengan azimut hasil rashdul kiblat sebesar $0^{\circ}$ 2'49,94'”.
\end{abstract}

Kata Kunci: Arah Kiblat; Geodetis; Ellipsoid; Ka'bah; Mercator

\begin{abstract}
[Title: Study of Geodetic Qibla Direction Determination] Qiblah is an important direction for Muslims exposes himself while performing prayers. Qiblah direction determination becomes a problem when the location of a place far away from the Kaaba. Therefore we need a method to determine the exact direction of Qibla in areas far from the Kaaba, in this study Semarang. This paper examines the difference of the direction of Qibla on three calculation surface: ellipsoid, spherical and mercator map. Then these Qibla direction accuracies on three calculation surface were compared with Qibla direction resulting from Rashdul Qibla Measurement. The difference of ellipsoid Qibla direction that has been corrected and spherical Qibla direction has a much smaller difference in the amount of 45.7 " compared with Mercator Qibla Direction. The difference of ellipsoid qibla direction and Qibla direction resulting from Rashdul Qibla Measurement is 00 7' 58,24'. While the difference of spherical Qibla direction and Qibla direction resulting from Rashdul Qibla Measurement is 00 2' 49,94'”.
\end{abstract}

Keywords: Qibla Direction; Geodetic; Ellipsoid; Kaaba; Mecator

\section{Pendahuluan}

Kiblat merupakan arah penting Umat Muslim menghadapkandirinya saat melakukan ibadah shalat. Dalam shalat umat muslim diwajibkan menghadap ke arah kiblat yaitu Ka'bah di Mekkah al Mukarrahmah. Kiblat berasal dari kata qibala (bahasa Arab) yang secara etimologis berarti bertemu dan qiblatan berarti arah pertemuan. Pengukuran arah kiblat kemudian menjadi permasalahan ketika lokasi suatu tempat jauh dari Ka'bah karena tidak dapat dilakukan pengamatan penglihatan secara langsung.

Alat dan metode pengukuran dan perhitungan arah kiblat bermacam-macam mulai dari peralatan yang paling sederhana yaitu kompas hingga peralatan pengukuran posisi teknologi GNSS (Global

\footnotetext{
* Penulis Korespondensi

e-mail: awa1210874@gmail.com
}

Navigation Satellite System) yang mempunyai ketelitian relatif lebih baik. Metode perhitungan juga berkembang yang semula menggunakan bola sebagai model bumi hitungan sekarang dengan penggunaan teknologi GNSS harus menggunakan ellipsoid (Abidin, 2007). Raharto dan Surya (2011) melakukan penentuan arah kiblat di Bandung dengan dua cara yaitu dengan pengamatan bayang - bayang Gnomon oleh matahari dan dengan perhitungan trigonometri bola. penentuan arah Kiblat dengan dua cara tersebut menghasilkan arah kiblat yang konsisten.

Metode penentuan arah kiblat dapat juga dengan memanfaatkan benda-benda langit yaitu posisi Matahari ketika berada di atas Ka'bah yang disebut dengan yaumu rashdul qiblat. Peristiwa ini hanya terjadi dua kali dalam setahun yaitu pada tanggal 27/28 Mei dan tanggal 15/16 Juli (Izzudin, 2012).

Rashdul kiblat merupakan metode pengamatan bayangan pada saat posisi matahari berada di atas Ka'bah atau ketika matahari berada di jalur yang 
menghubungkan antara Ka'bah dengan suatu tempat. Pada setiap tanggal 28 Mei dan tanggal 16 Juli, semua bayangan benda yang tegak lurus di permukaan bumi yang terkena sinar matahari akan menunjukkan arah kiblat. Berdasarkan pada deklinasi matahari yaitu pergerakan matahari ke utara dan selatan bumi yang berubah setiap harinya, waktu rashdul kiblat dapat ditentukan. Rashdul kiblat ini memperhitungkan posisi matahari ketika berada tepat di atas Ka'bah walaupun posisinya sedikit condong ke sebelah utara atau sebelah selatan Ka'bah. Pada saat itu setiap benda yang berdiri tegak lurus di atas permukaan bumi, bayangannya akan mengarah ke Ka'bah (Izzudin, 2012).

Pada awal tahun 2010 muncul isu pergeseran arah kiblat akibat pergeseran lempengan bumi dan adanya gempa bumi. Terkait permasalahan tersebut, Komisi Fatwa Majelis Ulama Indonesia Pusat mengeluarkan Fatwa MUI No. 3 Tahun 2010 tentang kiblat Indonesia arah barat yang kemudian direvisi dengan Fatwa MUI No. 5 Tahun 2010 tentang arah kiblat yang secara substansial memberikan pemahaman perlu adanya perhitungan arah kiblat, bukan hanya sekedar arah barat (Izzudin, 2012).

Pekerjaan penentuan arah kiblat pada dasarnya terdiri dari dua macam, yaitu bagaimana cara menghitung arah kiblat dari suatu titik/lokasi dan bagaimana membawa arah kiblat yang sudah didapat tersebut ke lapangan. Permasalahan tersebut pada saat ini masih terjadi dalam masyarakat di Indonesia, sehingga dalam penentuan arah kiblat masih ditemukan cara praktis yaitu menetapkan arah kiblat ke arah barat.

Model bumi yang digunakan untuk perhitungan posisi geodesi (koordinat, jarak dan sudut/azimut/arah) adalah bola, ellipsoid dan bidang datar. Oleh karena itu hitungan arah kiblat dapat dilakukan di atas bidang referensi bola, ellipsoid dan peta (bidang datar) (Kahar, 2008). Dengan bidang hitungan yang berbeda dan metode hitungan mengakibatkan arah kiblat yang dihasilkan di ketiga bidang tersebut berbeda. Bentuk bumi sendiri lebih mendekati ke bentuk ellipsoid, sehingga diasumsikan hitungan posisi di atas ellipsoid lebih akurat dibandingkan di atas bola dan peta.

Wardhani dkk. (2012) melakukan perhitungan arah kiblat dengan menggunakan perhitungan di atas bola dibandingkan pengukuran dengan kompas. Selisih kedua metode tersebut sangat besar berkisar $7^{0}$ s.d. $17^{0}$. Oleh karena itu tidak disarankan pengukuran arah iblat dengan menggunakan kompas. Izzudin (2012) melakukan perhitungan arah kiblat di atas bidang bola dan ellipsoid. Akurasi azimut didapat dari sudut cakupan azimut untuk arah kiblat berupa bangunan Kabah, Masjidil Haram dan Kota Mekkah. Sudut cakupan azimut yang didapat jika arah kiblat adalah bangunan kabah berkisar pada angka di bawah 1". Sedangkan untuk Masjidil Haram berkisar orde detik, untuk Kota Mekkah di orde menit. Perhitungan tersebut didasarkan pada Hadist Nabi bahwa arah kiblat untuk orang-orang yang berada di dalam Masjidil Haram adalah bangunan Kabah, untuk orangorang di Kota Mekkah adalah Masjidil Haram sedangkan untuk yang berada di luar Kota Mekkah adalah Kota Mekkah.

Nugroho dan Khomsin (2013) melakukan perhitungan arah kiblat di Kota Surabaya dengan menggunakan bidang perhitungan bola dan ellipsoid. Arah kiblat pada bidang bola memiliki perbedaan sebesar 1'8,7949" - 1'21,5281" terhadap arah kiblat pada bidang ellipsoid. Sedangkan, arah kiblat pada bidang ellipsoid dengan menggunakan rumus segitiga bola memiliki perbedaan sebesar 7', 17,581"- 7', 18,9383" terhadap arah kiblat pada bidang ellipsoid.

Marwadi (2014) melakukan perhitungan arah kiblat untuk kota Banjarnegara, Purbalingga, Banyumas, Cilacap dan Kebumen di atas bidang perhitungan ellipsoid dengan menggunakan rumus vincenty. Arah kiblat yang dihasilkan jika dibandingkan dengan arah kiblat yang selama ini dipedomani (Kementerian Agama setempat), terdapat selisih rata-rata $0^{\circ} 7^{\prime} 32.74$ '”

Penelitian-penelitian di atas belum ada yang melakukan pemasangan arah kiblat di lapangan yang merupakan salah satu masalah dalam penentuan arah kiblat dan membandingkan akurasinya dengan penentuan arah kiblat metode rashdul qiblat. Oleh karena itu selain menghitung arah kiblat di ketiga bidang referensi (bola, ellipsoid dan Peta Mercator) penelitian ini juga akan melakukan pemasangan arah kiblat di lapangan dan hasilnya dibandingkan dengan metode rashdul qiblat.

\section{Metode Penelitian \\ 2.1. Lokasi Penelitian}

Lokasi penelitian penentuan arah kiblat adalah di Kota Semarang. Sedangkan titik-titik pengamatan GNSS yang digunakan untuk pengukuran rashdul kiblat berada di area Kampus Undip Tembalang. Pengukuran GNSS dilakukan pada BM P1 dan P2. BM P1 digunakan sebagai titik yang akan dihitung arah kiblatnya. Sedangkan BM P2 digunakan sebagai acuan untuk pemasangan arah kiblat di lapangan.

\subsection{Alat dan Bahan}

Pengukuran koordinat $\mathrm{BM} \quad \mathrm{P} 1$ dan $\mathrm{P} 2$ menggunakan Receiver GNSS Topcon Hiper II. Hasil pengukuran diikatkan ke Stasiun CORS CSEM milik Badan Informasi Geospasial. Data RINEX Stasiun CORS CSEM didapat dengan membeli ke Badan Informasi Geospasial. Total station digunakan untuk pengukuran arah kiblat metode rashdul kiblat.

Perangkat lunak Adjust digunakan untuk menghitung arah kiblat di atas ellipsoid, sedangkan Matlab digunakan untuk menghitung arah kiblat di atas bola dan peta Mercator. Koordinat Geodetis Ka'bah dan Kota Mekkah diperoleh dari penelitian Izuddin (2012). 


\subsection{Tahapan Penelitian}

Tahapan Penelitian ini dapat dilihat pada diagram alir pada Gambar 1.

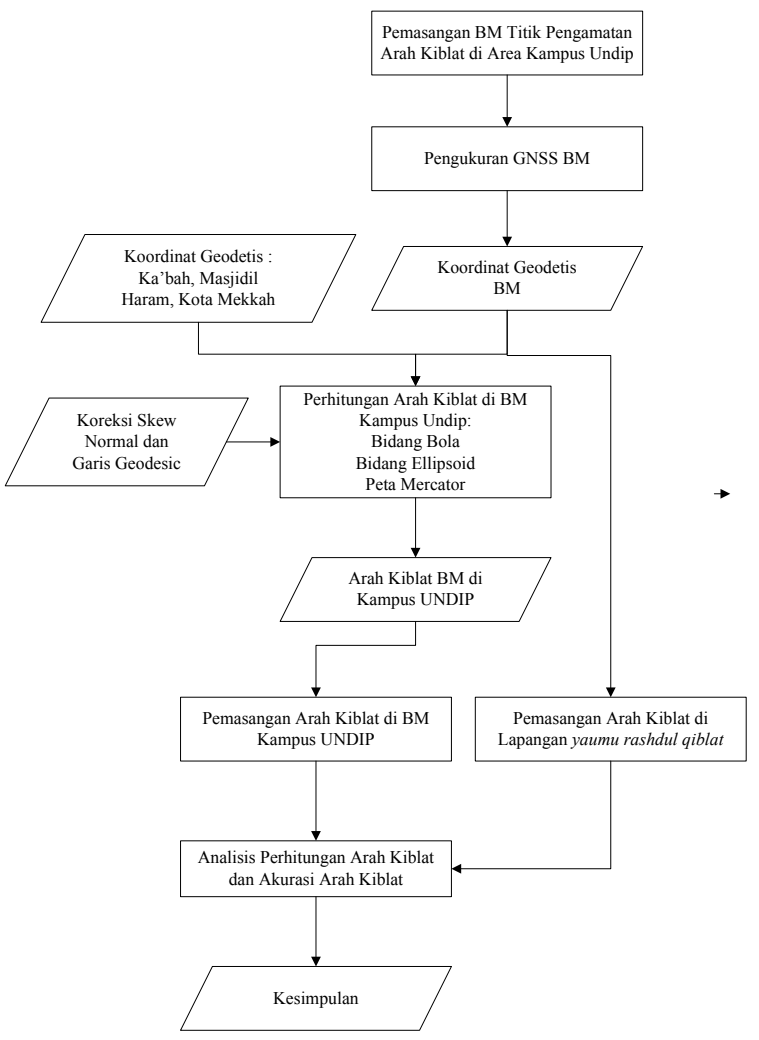

Gambar 1. Diagram Alir Penelitian

Pengukuran BM P1 dan P2 dilakukan dengan pengukuran GNSS metode Statik diferensial. Perhitungan koordinat P1'dan P2 dilakukan dengan acuan titik CORS CSEM dengan sistem koordinat SRGI 2013. Perhitungan arah kiblat dilakukan pada tiga bidang hitungan yaitu ellipsoid, bola dan peta Mercator di titik P1. Arah kiblat pada bidang ellipsoid dikoreksi dengan koreksi skew normal dan garis geodesic. Ketiga arah kiblat tersebut dipasang di lapangan dengan acuan titik P2.

Sistem Koordinat yang digunakan dalam ellipsoid biasanya disebut Sistem Koordinat Geodetis, yang dinyatakan dengan notasi Lintang, Bujur dan tinggi $(\vartheta, \lambda, h)$ (Bomford, 2010). Dalam Sistem Koordinat Geodetis besaran bujur suatu titik adalah sudut yang dibentuk dari bujur $0^{0}$ (Bujur Greenwich) s.d. bujur yang melewati titik tersebut. Lintang suatu titik adalah sudut yang dibentuk oleh bidang equator garis normal yang melewati titik tersebut. Arah kiblat dari titik P1 di bidang ellipsoid adalah sudut yang dibentuk oleh arah utara yang melewati titik P1 searah jarum jam sampai garis terpendek dari titik P1 ke Ka'bah. Metode perhitungan arah kiblat di atas ellipsoid menggunakan metode Vincenty (Vincenty, 1975). Arah kiblat dari titik P1 di bidang bola adalah sudut yang dibentuk oleh arah utara yang melewati titik P1 searah jarum jam sampai garis terpendek dari titik P1 ke Ka'bah. Metode perhitungan arah kiblat di atas bola menggunakan metode segitiga bola (Basuki, 2011).

Hitungan arah kiblat di atas bidang bola mengunakan lintang reduksi. Hal ini dilakukan karena lintang yang dihasilkan dari pengukuran GNSS adalah lintang geodetis yang mengacu pada bidang ellipsoid (Hofmann dan Wellenhof, 2008). Pemasangan arah kiblat metode rashdul kiblat dilakukan pada tanggal 28 Mei 2016. Arah kiblat dipasang di titik P1 dengan acuan P2.

\section{Hasil dan Pembahasan}

\subsection{Pengukuran GNSS}

Pengukuran GNSS dilakukan selama kurang lebih empat jam pada tanggal 22 Juli 2016. Metode pengukuran adalah statik diferensial. Titik GNSS yang dijadikan sebagai acuan adalah titik GNSS CORS CSEM milik Badan Informasi Geospasial.

Hasil pengukuran GNSS adalah koordinat geodetis titik P1 dan P2 yang dapat dilihat pada Tabel 1.

Tabel 1. Koordinat Geodetis hasil Pengukuran GNSS

\begin{tabular}{clc}
\hline Titik & \multicolumn{1}{c}{ Lintang } & \multicolumn{1}{c}{ Bujur } \\
\hline CSEM & $6^{0} 59^{\prime} 14,17^{\prime}$ LS & $110^{0} 22^{\prime} 36,97^{\prime \prime} \mathrm{BT}$ \\
P1 & $7^{0} 3^{\prime} 2,26841^{\prime \prime} \mathrm{LS}$ & $110^{0} 26^{\prime} 21,027633^{\prime} \mathrm{BT}$ \\
P2 & $7^{0} 3^{\prime} 1,59027^{\prime}$ LS & $110^{0} 26^{\prime} 21,34334^{\prime \prime} \mathrm{BT}$ \\
\hline
\end{tabular}

\subsection{Arah Kiblat}

Arah kiblat di titik P1 dihitung pada tiga bidang hitungan yaitu: ellipsoid, bola dan bidang datar (peta mercator). Koordinat Ka'bah yang digunakan diambil dari penelitian Izudin (2012) yaitu $21^{0} 25^{\text {, }}$ 21,17' LU, 39 49 ' 34,56" BT. Hitungan arah kiblat di atas ellipsoid dilakukan dengan metode vincenty, di atas bola dengan segitiga bola menggunakan lintang reduksi serta di atas peta mercator dengan rumus azimut bidang datar. Lintang reduksi titik P1 didapat $7^{0} 1$ ' 38,01875" LS dan Ka'bah $21^{0} 21$ ' 25,92573" LU. Hasil arah kiblat di titik P1 pada ketiga bidang dapat dilihat pada Tabel 2.

Tabel 2. Arah Kiblat

\begin{tabular}{cc}
\hline Bidang Hitungan & Arah Kiblat \\
\hline Ellipsoid & $294^{0} 23^{\prime} 15,99^{\prime \prime}$ \\
Bola & $294^{0} 26^{\prime} 26,68^{\prime \prime}$ \\
Peta Mercator & $292^{0} 12^{\prime} 9,53^{\prime \prime}$ \\
\hline
\end{tabular}

Dari ketiga arah kiblat yang diperoleh beda di atas ellipsoid dengan bola paling kecil yaitu $0^{0} \quad 3$, 10,69". Jika arah kiblat di atas ellipsoid dikoreksi dengan koreksi skew normal yang diperoleh sebesar 0,021" dan koreksi garis geodesic sebesar -144,97" maka azimut lapangan menjadi $294^{0} 25$, 40,98". Sehingga selisihnya menjadi 45,7”. 


\subsection{Rashdul Kiblat}

Pengukuran rashdul kiblat dilakukan pada tanggal 28 Mei 2016 dan 16 Juli 2016 di titik P1. Pengukuran pertama bayangan arah kiblat pada tanggal 28 Mei 2016 masih dapat terlihat meskipun samar-samar karena intensitas cahaya matahari yang sudah melemah. Sedangkan pada 16 Juli 2016 cuaca mendung dan matahari sudah terlalu rendah sehingga bayangan arah kiblat tidak dapat diperoleh.

Bayangan arah kiblat yang diperoleh di titik P1, diukur sudutnya, yaitu sudut P2-P1-ArahKiblat. Sudut yang diperoleh sebesar $269^{\circ} 37^{\prime}$ 4". Azimut titik P1 ke P2 di atas ellipsoid sebesar $24^{0} 56^{\prime} 35,22^{\prime \prime}$, sehingga arah rasdul kiblat (untuk ellipsoid) diperoleh $294^{0} 33$ '39.22". Azimut titik P1 ke P2 di atas bola sebesar $24^{0} 52$ ' 12,62", sehingga azimut rasdul kiblat (untuk bola) diperoleh 294 29 ' 16.62". Azimut rashdul kiblat untuk ellipsoid dan bola berbeda karena azimut P1 ke P2 di atas ellipsoid dihitung dengan metode vincenty, sedangkan bola dengan metode segitiga bola lintang reduksi.

Beda arah rashdul kiblat (untuk ellipsoid) sebesar $294^{0} 33$ '39.22"dengan arah kiblat di ellipsoid yang sudah dikoreksi ke lapangan sebesar $294^{0} 25^{\prime}$ 40,98" adalah $0^{0} 7$ ' 58,24". Beda azimut rashdul kiblat (untuk bola) sebesar $294^{\circ} 29$ ' 16.62"dengan azimut metode segitiga bola dengan lintang reduksi sebesar $294^{0} 26^{\prime} 26,68^{\prime \prime}$ adalah $0^{0} 2$ ' 49,94'.

\subsection{Toleransi Ketelitian Arah Kiblat}

Toleransi ketelitian arah kiblat mengacu pada sebuah Hadits Nabi Muhammad SAW yang diriwayatkan oleh al-Baihaqi dari Abu Hurairah: "Baitullah adalah kiblat bagi orang-orang di Masjidil Haram. Masjidil Haram adalah kiblat bagi orangorang penduduk Tanah Haram (Mekkah). Dan Tanah Haram adalah kiblat bagi semua umatku di bumi, baik di Barat maupun di Timur". Dari hadits tersebut, untuk wilayah Indonesia berarti arah kiblatnya adalah Kota Mekkah (Rohmat, 2012). Dari ketentuan di atas maka dihitung arah kiblat dari titik P1 ke batas paling utara dan batas selatan Kota Mekkah. Koordinat Kota Mekkah didapat dari Izuddin (2012). Hasil perhitungan dapat dilihat pada Tabel 3.

Tabel 3. Arah Kiblat ke Kota Mekkah

\begin{tabular}{|c|c|c|c|c|}
\hline \multirow[b]{2}{*}{ Arah } & \multicolumn{2}{|c|}{ Koordinat } & \multirow[b]{2}{*}{ Azimut } & \multirow{2}{*}{$\begin{array}{c}\text { Selisih } \\
\text { terhadap } \\
\text { Ka'bah }\end{array}$} \\
\hline & Lintang & Bujur & & \\
\hline Ka'bah & $\begin{array}{c}21^{0} 25^{\prime} \\
21,17^{\prime \prime} \mathrm{LU}\end{array}$ & $\begin{array}{c}39^{0} 49^{\prime} \\
34,56^{\prime \prime} \mathrm{BT}\end{array}$ & $\begin{array}{c}294^{0} 23^{\prime} \\
15,99^{\prime \prime}\end{array}$ & 0 \\
\hline Utara & $21^{0} 28^{\prime}$ & $39^{0} 49^{\prime}$ & $294^{0} 26^{\prime}$ & $0^{0} 3{ }^{\prime}$ \\
\hline Mekkah & 38,21 " $\mathrm{LU}$ & 57,14 ” BT & 38,79”' & $22.8^{\prime \prime}$ \\
\hline Selatan & $21^{0} 23$ & $39^{\circ} 49^{\prime}$ & $294^{0} 20^{\prime}$ & $0^{0} 2^{\prime}$ \\
\hline Mekkah & 8,56" LU & 20,06 " BT & $59,66 "$ & 16.33" \\
\hline
\end{tabular}

Dari hitugan arah kiblat ke Kota Mekkah, maka ketelitian pengamatan arah kiblat dari Kota Semarang berkisar $0^{\circ} 3$, 22.8" ke arah utara Mekkah dan $0^{0} 2$ ' $16.33^{\prime}$ ' ke arah selatan mekkah. Atau paling tidak pengukuran arah kiblat harus dalam rentang 5 , 39.13".

\section{Kesimpulan}

Perhitungan arah kiblat dengan menggunakan tiga bidang hitungan: ellipsoid, bola dan peta mercator menghasilkan arah kiblat di atas ellipsoid dan bola mempunyai perbedaan yang jauh lebih kecil yaitu jika dibandingkan dengan azimut pada bidang datar Peta Mercator. Arah kiblat hasil hitungan di atas bola paling mendekati arah kiblat metode rasdul kiblat dibandingkan dua bidang hitungan yang lain.

\section{Ucapan Terima Kasih}

Penulis mengucapkan terima kasih kepada Fakultas Teknik dan Program Studi Teknik Geodesi atas dana Hibah Penelitian Dasar yang digunakan dalam penelitian makalah ini.

\section{Daftar Pustaka}

Abidin, H.Z. (2007). Penentuan Posisi dengan GPS dan Aplikasinya. Jakarta: PT. Pradnya Paramita.

Basuki, S. (2011). Ilmu Ukur Tanah (Edisi Revisi). Yoyakarta: Gadjah Mada University Press.

Bomford. (2010). Geodesy. Nabu Press.

Hofmann and Wellenhof. (2008). GNSS - Global Navigation Satellite Systems: GPS, GLONASS, Galileo, and more. New York: SpringerWien.

Izzudin, A. (2012). Metode Penentuan Arah Kiblat dan Akurasinya. Pada Annual International Conference on Islamic Studies XII. Surabaya: IAIN Sunan Ampel.

Kahar, J. (2008). Geodesi. Bandung: Penerbit ITB.

Marwadi. (2014). Aplikasi Teori Geodesi dalam Perhitungan Arah Kiblat: Studi Untuk Kota Banjarnegara, Purbalingga, Banyumas, Cilacap, Kebumen. Jurnal Al-Manahij, 8(2), 329-351.

Nugroho, AP dan Khomsin. (2013). Analisis Perbedaan Perhitungan Arah Kiblat pada Bidang Spheroid dan Ellipsoid dengan Menggunakan Data Koordinat GPS. Jurnal Teknik POMITS 2(1).

Raharto, M dan Surya, DJA. 2011. Telaah Penentuan Arah Kiblat dengan Perhitungan Trigonometri Bola dan Bayang-Bayang Gnomon oleh Matahari. Jurnal Fisika Himpunan Fisika Indonesia, 11 (1): 23-29.

Rohmat. 2012. Arah Kiblat dengan Matahari. Jurnal Asas, 4(2): 87-101.

Vincenty, T. (1975). Direct and Inverse Solutions of Geodesics on the Ellipsoid with Application of Nested Equations. Survey Review, XXII(176): 88-93.

Wardhani, G.K., Kurniawan, W., Gulita, H.D. \& Kristiyanto, W.H. (2012). Pengujian Pemberlakuan Rumus Segitiga Bola dalam Penentuan Arah Kiblat Sholat. Pada Seminar Nasional Sains dan Pendidikan Sains VII. Salatiga: Universitas Kristen Satya Wacana. 
Teknik, 37 (2), 2016, 88 